\title{
A new approach for the acquisition of trauma surgical skills: an OSCE type of simulation training program
}

\author{
Catalina Ortiz ${ }^{1,2} \cdot$ Javier Vela $^{1,2} \cdot$ Caterina Contreras $^{1,2} \cdot$ Francisca Belmar $^{1,2} \cdot$ Ivan Paul $^{1,2} \cdot$ Analia Zinco $^{3}$. \\ Juan Pablo Ramos ${ }^{3} \cdot$ Pablo Ottolino $^{2,3} \cdot$ Pablo Achurra $^{1,2} \cdot$ Nicolas Jarufe $^{4} \cdot$ Adnan Alseidi $^{5} \cdot$ Julian Varas ${ }^{1,2}([)$
}

Received: 15 September 2021 / Accepted: 7 February 2022 / Published online: 2 March 2022

(c) The Author(s), under exclusive licence to Springer Science+Business Media, LLC, part of Springer Nature 2022

\begin{abstract}
Background Worldwide, trauma-related deaths are one of the main causes of mortality. Appropriate surgical treatment is crucial to prevent mortality, however, in the past decade, general surgery residents' exposure to trauma cases has decreased, particularly since the COVID-19 pandemic. In this context, accessible simulation-based training scenarios are essential. Methods A low-cost, previously tested OSCE scenario for the evaluation of surgical skills in trauma was implemented as part of a short training boot camp for residents and recently graduated surgeons. The following stations were included bowel anastomosis, vascular anastomosis, penetrating lung injury, penetrating cardiac injury, and gastric perforation (laparoscopic suturing). A total of 75 participants from 15 different programs were recruited. Each station was videotaped in high definition and assessed in a remote and asynchronous manner. The level of competency was assessed through global and specific rating scales alongside procedural times. Self-confidence to perform the procedure as the leading surgeon was evaluated before and after training.

Results Statistically significant differences were found in pre-training scores between groups for all stations. The lowest scores were obtained in the cardiac and lung injury stations. After training, participants significantly increased their level of competence in both grading systems. Procedural times for the pulmonary tractotomy, bowel anastomosis, and vascular anastomosis stations increased after training. A significant improvement in self-confidence was shown in all stations.

Conclusion An OSCE scenario for training surgical skills in trauma was effective in improving proficiency level and selfconfidence. Low pre-training scores and level of confidence in the cardiac and lung injury stations represent a deficit in residency programs that should be addressed. The incorporation of simulation-based teaching tools at early stages in residency would be beneficial when future surgeons face extremely severe trauma scenarios.
\end{abstract}

Keywords Trauma surgery $\cdot$ Simulation training $\cdot$ Surgical training $\cdot$ Surgical education technology

Globally, over 1 billion people suffer traumatic injuries, being responsible for 6 million deaths annually [1]. Mortality

Julian Varas

jevaras@uc.cl

1 Department of Digestive Surgery, Pontificia Universidad Católica de Chile, Santiago, Chile

2 Experimental Surgery and Simulation Center, Faculty of Medicine, Pontificia Universidad Católica de Chile, Santiago, Chile

3 Trauma Surgery Department, Hospital Sótero del Río, Santiago, Chile

4 Department of Surgery, Clínica Las Condes, Santiago, Chile

5 Department of Surgery, University of California San Francisco, San Francisco, USA is concentrated in the first hours and is often caused by massive bleeding from big vessels or highly irrigated organs; creating fatal outcomes that are preventable with prompt and effective surgical care [2-5].

In rural areas and low-income countries, young general surgeons with little to no experience in independent practice are often on call at emergency services during non-business hours, which is when the highest number of accidents occur. However, nationally and internationally, it has been described that general surgeons do not feel qualified to take on this task [6]. In North America, up to $40 \%$ of surgical residents do not feel confident enough for their independent practice even though they spend 5 years training as residents $[6,7]$. Regulations limiting residents' training hours and the advent of non-operative management have been among the 
main reasons to explain this situation $[8,9]$. In the past year, the COVID-19 pandemic has aggravated this to an unprecedented extent [10]. A significant reduction in surgical volume alongside severe shortages of personnel requiring residents to be redistributed to roles that involve taking care of non-surgical patients has drastically diminished residents' caseload exposure [11, 12]. Even though programs have implemented different strategies to cope with these difficulties, the level at which it has hindered the quality of surgical training has yet to be seen. In this context, and considering that simulation-based teaching tools have proven to be effective in a variety of settings, the incorporation of simulation scenarios is even more crucial than before [13]. However, elevated costs can affect simulation tools' availability. Therefore, easy-to-access and easy-to-implement alternatives are especially relevant. In previous work, our team developed a low-cost Objective Structured Clinical Examination (OSCE) scenario for the evaluation of surgical skills in trauma surgery [14]. In this article we implemented the OSCE as a training tool for residents, measuring the improvement of skills, and evaluating the impact it had on self-perception of competence.

\section{Methods}

An observational study was designed. Participants were invited to join in a three-day trauma surgical skills boot camp. Pre- and post-training performance were assessed alongside self-confidence to independently perform the procedures.

\section{Recruiting}

Surgical residents at different levels of training from 15 different programs across the country and recently graduated general surgeons from several regions were invited to participate. A minimum sample size of 11 participants per group was established using a power of 0.8 and alpha of 0.05 .

Therefore, 75 participants were recruited and distributed into five groups of 15 trainees each to be enrolled in a 3-day training program. Traveling and hosting expenses were covered.

\section{Assessment and training}

Our team previously designed and tested under the Messick validity framework an Objective Structured Clinical Examination scenario (OSCE) for evaluation of surgical skills in trauma $[14,15]$. The OSCE was now used to assess participants' performance and guide their training.
It consisted of 5 simulation-based stations: bowel anastomosis (hand-sewn side- to-side entero-enterostomy on a bovine bowel), vascular anastomosis (end-to-end handsewn anastomosis in a perfused $5 \mathrm{~mm}$ porcine carotid or iliac artery), laparoscopic suturing (laparoscopic suturing of gastric perforation in an ex vivo porcine stomach model), penetrating lung injury (hand-sewn tractotomy in ex vivo ventilated porcine lungs), and penetrating cardiac injury (bleeding control and suturing of three standardized injuries: right atrium, right ventricle away from the coronary artery, and left ventricle in the vicinity of the coronary artery in a perfused ex vivo porcine model). The cardiac model was perfused using a pulsatile roller pump connected to the aorta, delivering up to $5 \mathrm{lt} / \mathrm{min}$ of fake blood, with a pumping heart effect of $120-140$ beats per minute [14, 16-18].

These procedures were selected due to their reported frequency in Chilean Hospitals [19, 20] and guidelines developed by the Chilean Society of Surgeons regarding the minimal competencies needed to be a general surgeon in Chile. This is due to the reality observed in most hospitals in Chile, which do not have specialized surgical trauma departments, or on-call teams for surgical specialists (vascular, cardiothoracic, or gastrointestinal surgeons). Therefore, most trauma-related surgeries in our country are performed by general surgeons.

Participants had 20 min to complete each station.

For pre- and post-training assessments, each procedure was recorded in high definition and blindly evaluated by experts in an asynchronous manner through a novel technology-enhanced learning platform [21, 22]. Participants were evaluated using a modified OSATS (Objective Structured Assessment of Technical Skills), a widely used global rating scale designed to assess proficiency in practical surgical skills [23]. The total score is based on subscores in five domains: respect for tissue, time and motion, instrument handling, the flow of operation and forward planning, and knowledge of the specific procedure. Each domain is assessed on a scale from 1 to 5 ; the maximum possible score for each station was 25 points. In addition, a task-specific rating scale (SRS) was developed according to experts' opinions on essential aspects that had to be included. This "checklist" type of assessment was specific to each station, with varying maximum scores.

A trauma surgery boot camp was designed, with training sessions guided by expert trauma surgeons from our institution. Participants were divided into groups to deliberately practice on the models while receiving direct feedback from experts. The training sessions lasted $2 \mathrm{~h}$ for each station. 


\section{Self-perception of skills}

A self-assessment survey was designed and applied before and after training. The survey contained Likert-type [24] questions regarding participants' self-perception of competence performing different trauma procedures as the leading surgeon [20].

\section{Statistical analysis}

Data were analyzed with RStudio ${ }^{\circledR}$ (2019 v1.2.5001 on base R, Boston, US) using nonparametric statistics. Pre- and post-training performance and self-confidence were compared using a paired, two-tailed Wilcoxon signed-rank test with an alpha set at 0.05 and a power of $80 \%$. To compare scores among groups, the Kruskal-Wallis test for multiple comparisons was used to assess whether there were significant differences among the groups in terms of scores and procedural times. The Dunn test for pairwise comparisons was used to determine in which groups the differences were statistically significant.

\section{Results}

Pre-training OSATS results showed statistically significant differences among the previous levels of expertise for the cardiac injury [postgraduate year 1 (PGY1) vs recently graduated surgeons (RGS), $p=0.0282$ ], bowel anastomosis [postgraduate year 2 (PGY2) vs postgraduate year 3 (PGY3) $p=0.0189$ ], and vascular anastomosis [PGY1 vs PGY3, $p=0.0423$ ] stations (Table 1 ). In the cardiac injury station, first-year residents got the lowest score of all stations, with a median of 15 points.

In terms of the SRS performance before training, bowel and vascular anastomosis stations showed significant differences in performance. For the bowel anastomosis station,
Median pre-training scores were very similar for all groups, however, there was 1 participant in the PGY2 group that got only 3 points. A statistically significant difference was found between that group when compared to PGY3 and RGS, which correlates with what was obtained with OSATS (Table 2).

In the vascular anastomosis station, statistically significant differences were also found, even though all groups got very similar pre-training scores.

As it is shown in Table 3, in terms of individual results, participants' achieved a statistically significant improvement after the boot camp in the majority of the stations, with $p$ values $<0.0001$ in both grading scales for the cardiac, lung, bowel, and vascular stations. For the laparoscopic suturing station, $p$ values of 0.0002 and 0.0006 were obtained for OSATS and SRS, respectively.

Regarding the time to complete the procedure, statistically, significant differences were found in all stations. In the pulmonary tractotomy, bowel anastomosis and vascular anastomosis stations' time to complete the procedure increased after training. The biggest increase was found in the lung injury station with a median increase of $6.11 \mathrm{~min}$ after training.

In the cardiac injury station, to better assess participants' performance timing was subdivided into bleeding control, ventricular repair, and atrial repair. Participants showed a statistically significant improvement in bleeding control and ventricular repair, diminishing the median time 35 and $27 \mathrm{~s}$, respectively (Table 4).

Regarding the self-perception of competence survey applied before and after training, all participants reported an improvement in self-confidence after training (Fig. 3, Table 5). In the bowel anastomosis station, the PGY1, PGY2, and PGY3 groups showed statistically significant improvements. The PGY1 group was more heterogeneous after training but showed the highest median improvement among all groups, while the PGY2 and PGY3

Table 1 OSATS pre-training

\begin{tabular}{llllll}
\hline Station & \multicolumn{2}{l}{ OSATS pre-training (range-median) } & \multirow{2}{l}{ Pairwise comparisons $(p$-value) } \\
\cline { 2 - 5 } & PGY1 & PGY2 & PGY3 & RGS & \\
\hline Penetrating cardiac injury & $10-22$ & $12-23$ & $13-24$ & $10-24$ & PGY1 vs RGS \\
& $(15)$ & $(17.5)$ & $(20)$ & $(20.5)$ & $p=0282$ \\
Penetrating lung injury & $14-22(17)$ & $15-23(18)$ & $15-24(18)$ & $14-25(18)$ & Non-significant \\
Bowel anastomosis & $17-24(22)$ & $16-24(20)$ & $17-25(23)$ & $17-25(23)$ & PGY2 vs PGY3 \\
& & & & & $p=0.0189$ \\
Laparoscopic suturing & $11-25(20)$ & $11-25(21)$ & $14-24(22)$ & $16-25(21-5)$ & Non-significant \\
Vascular anastomosis & $11-19$ & $13-22(18.5)$ & $14-23(20)$ & $11-24$ & PGY1 vs PGY3 $p=0.0423$ \\
& $(17)$ & & & $(19)$ & \\
\hline
\end{tabular}

Comparison among groups according to the previous level of expertise

$P G Y 1$ postgraduate year $1, P G Y 2$ postgraduate year 2, $P G Y 3$ postgraduate year $3, R G S$ recently graduated surgeons 
Table 2 SRS pre-training

\begin{tabular}{|c|c|c|c|c|c|}
\hline \multirow[t]{2}{*}{ Station } & \multicolumn{4}{|c|}{ SRS pre-training range (median) } & \multirow{2}{*}{$\begin{array}{l}\text { Pairwise } \\
\text { comparisons } \\
\text { ( } p \text {-value) }\end{array}$} \\
\hline & PGY1 & PGY2 & PGY3 & RGS & \\
\hline Penetrating cardiac injury & $2-6(4)$ & $2-7(4)$ & $3-7(5.5)$ & $2-7(5)$ & Non-significant \\
\hline Penetrating lung injury & $0-7(2)$ & $0-8(3)$ & $0-8(4)$ & $1-8(4.5)$ & Non-significant \\
\hline Bowel anastomosis & $7-14(13)$ & $3-14(11)$ & $8-15(13)$ & $8-15(13)$ & $\begin{array}{l}\text { PGY2-RGS } \\
p=0.0283 \\
\text { PGY2-PGY3 } \\
p=0.0034\end{array}$ \\
\hline Laparoscopic suturing & $13-21(17)$ & $18-21(18)$ & 14-21 (19.5) & $14-21(20)$ & Non-significant \\
\hline Vascular anastomosis & $16-23(21)$ & $18-28(21.5)$ & $18-28(23)$ & $18-27(23)$ & $\begin{array}{l}\text { PGY1 vs PGY3 } \\
p=0.0116\end{array}$ \\
\hline
\end{tabular}

Comparison among groups according to the previous level of expertise

$P G Y 1$ postgraduate year $1, P G Y 2$ postgraduate year $2, P G Y 3$ postgraduate year $3, R G S$ recently graduated surgeons

groups improved median scores and reduced interquartile range. Even though non-statistically significant, the RGS started with the highest median level of confidence, and after training the group dispersion was also reduced.

For the Vascular injury and lung Injury station, all groups improved median scores with similar levels of dispersion.

In the cardiac injury station, all groups improved their median level of confidence with the PGY-1 showing almost no dispersion before training, since most participants rated their confidence level as 1 , and only 3 as 2 (the lowest confidence level among all stations). The highest heterogeneity is shown in the PGY-3 group, with results ranging from 1 to 5. Finally, in the laparoscopic suturing station, all groups improved their median level of confidence, with the highest dispersion shown in the first 2 years of residency.

\section{Discussion}

As it was previously stated, the importance of developing a low-cost, easy-to-access trauma surgery skills training system is crucial to impact the global burden of trauma injuries, which is particularly important in middle to lowincome countries. OSCE scenarios have previously shown to be effective assessment tools for practical skills in medicine, which aligns with previous work developed by our team in which we designed and tested an OSCE scenario for the evaluation of trauma surgical skills [14]. This OSCE type of training system has considerably lower costs than other training courses available in our country, such as the American College of Surgeons Advanced Trauma Operative Management (ATOM) that cost up to 1.000 USD in our country [25]. In comparison, the system that we propose has an estimated cost of 330 USD per participant (Table 6).

In this article we aimed to evaluate the OSCE stations as a training system, testing it in participants with different backgrounds and levels of training. The assessment tools used for this OSCE contemplated the widely validated global rating scale OSATS, and task-specific rating scales (SRS) for each procedure. The SRS were developed based on the opinion of experts at our institution.

The results showed participants significantly improved their performance after a training session with the models (Figs. 1 and 2), improvements that were particularly noticeable in the cardiac, pulmonary, bowel, and vascular stations. When analyzing procedural times (Table 7), it is interesting to notice that in three stations (pulmonary, bowel, and vascular anastomosis) time significantly increased after training. This could be a reflection of a deficiency in participants' previous knowledge of the technique, meaning they had to "learn" how to perform those procedures in the boot camp instead of practicing a previously acquired skill. These findings align with previous work done by Vela et al. that showed a very low level of preparedness in general surgeons to deal with complex trauma cases [20]. Particularly noticeable were the results obtained in the pulmonary tractotomy station, which is a procedure not often performed by general surgery residents, and a median increase of $6.11 \mathrm{~min}$ was observed. The cardiac injury and laparoscopic suturing stations showed significant reductions in procedural times, which may indicate participants had a previous notion on how to perform those procedures and used their training time to become more proficient. It is particularly significant from a clinical perspective a 35 -s reduction in time to control myocardial bleeding.

In terms of participants' scores according to the previous level of expertise (Table 8), significant differences in performance were found among the 4 groups in the cardiac injury, bowel anastomosis, and vascular anastomosis stations. Those differences disappeared after training, except for the cardiac injury station, where statistically significant differences among groups persisted. 


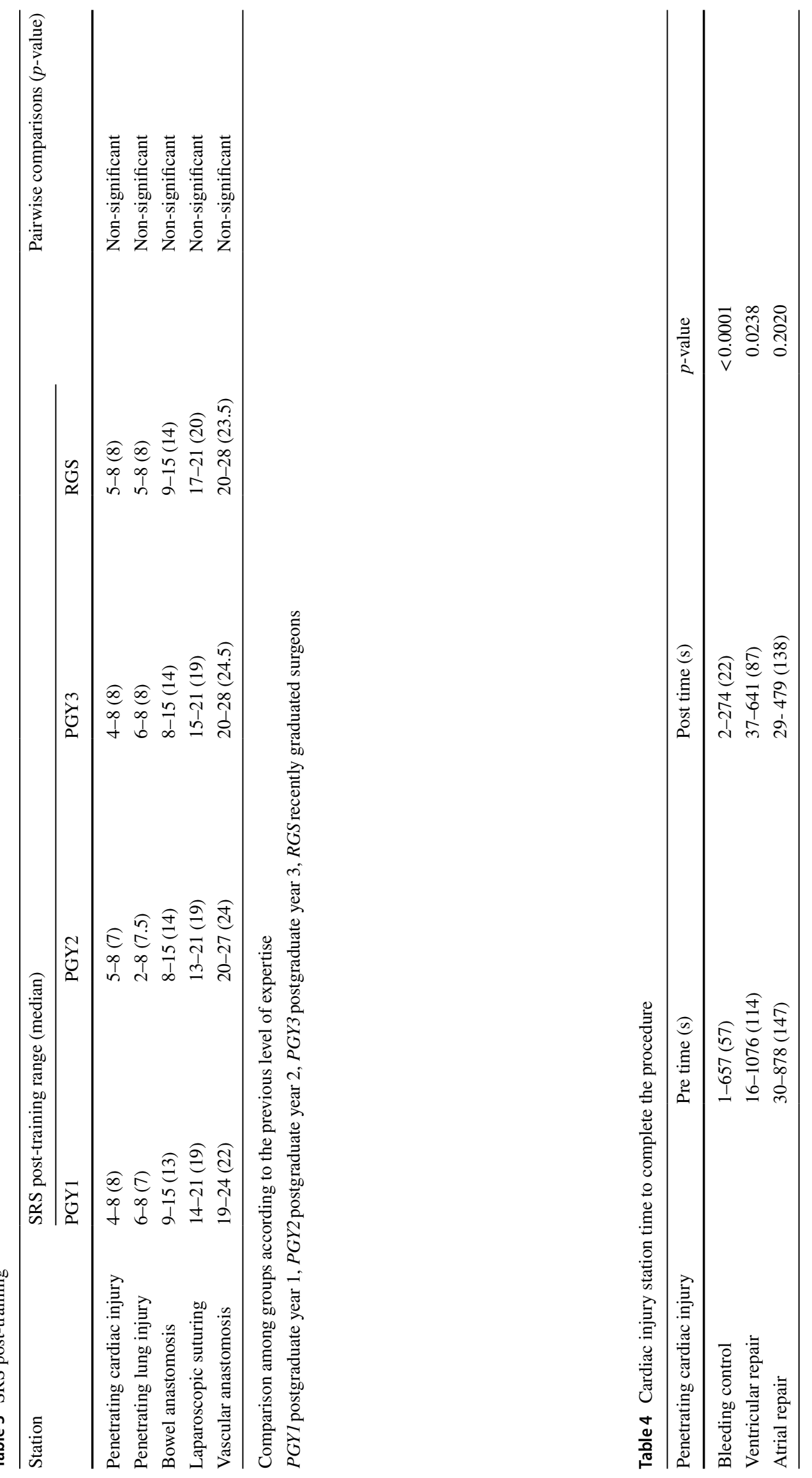




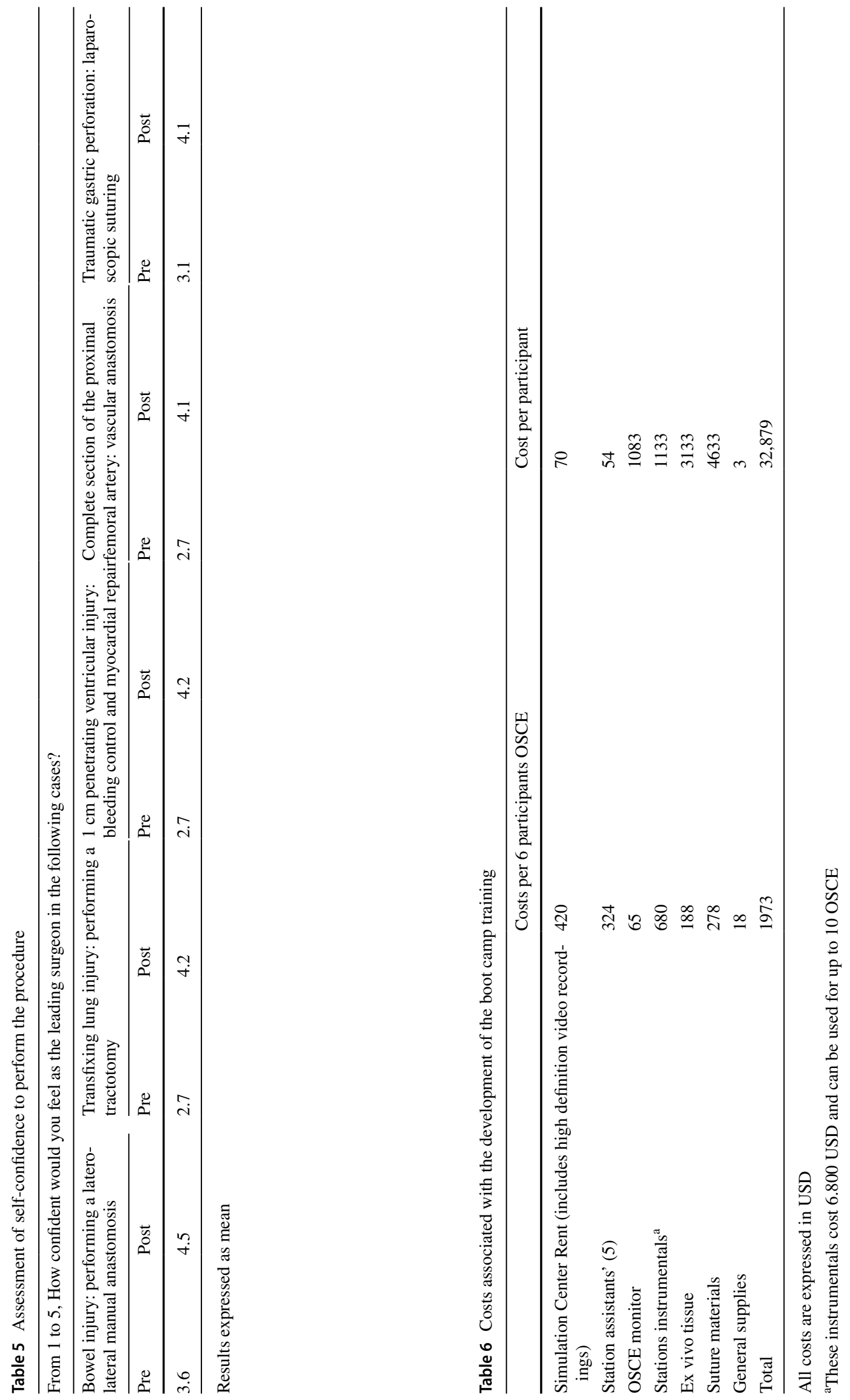


Regarding self-perception of competence, overall participants reported an improvement in self-confidence (Table 6, Fig. 3). In the bowel anastomosis station, residents improved their confidence level alongside reducing the group's dispersion, except for first-year residents, which was also the group with the biggest median improvement and higher dispersion. A possible explanation for this could be that as residents move forward on their training, they tend to level up in this technique, as they possess more tools to reach a successful learning curve. Something similar happened in the laparoscopic suturing station, where higher heterogeneity was observed during the first two years of residency. On the other hand, in the cardiac injury station, the highest level of dispersion was shown in the PGY3 group which alongside extremely low pre-training results obtained by PGY1 might reflect that abilities required for a successful learning curve in this procedure are acquired later during the course of training.

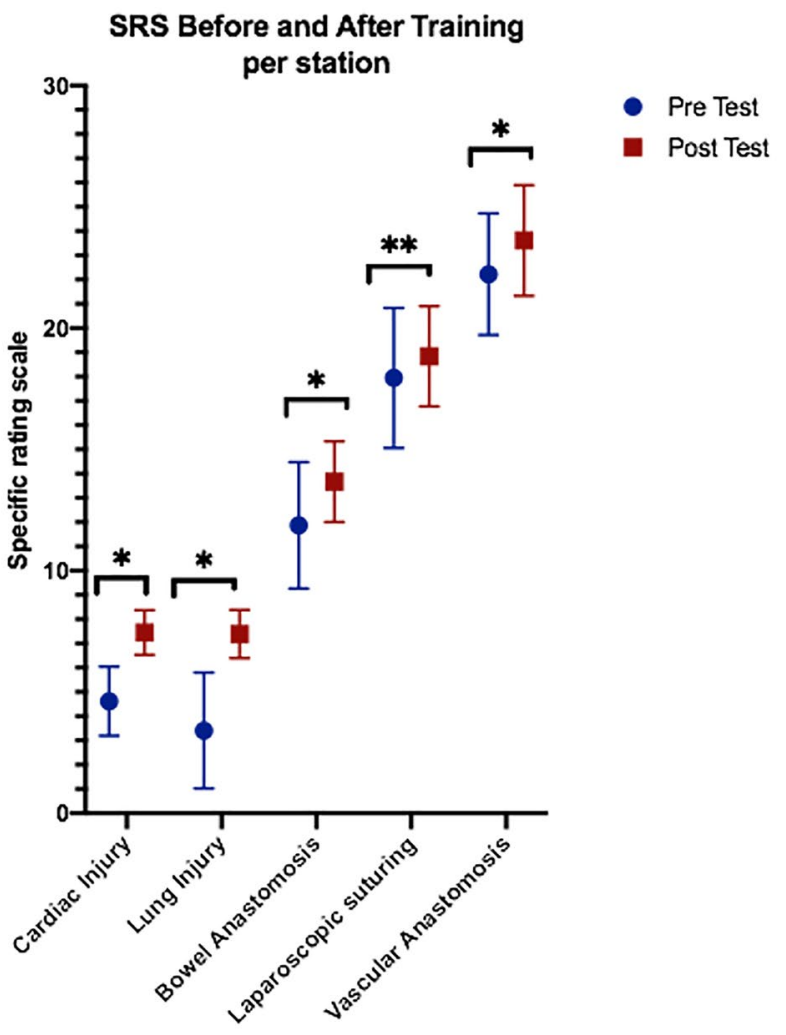

SRS individual scores before and after training.

$*=p<0.01$

$* *=p<0.001$

Fig. 2 SRS individual scores before and after training. $* p$-value $<0.01, * * p$-value $<0.001$

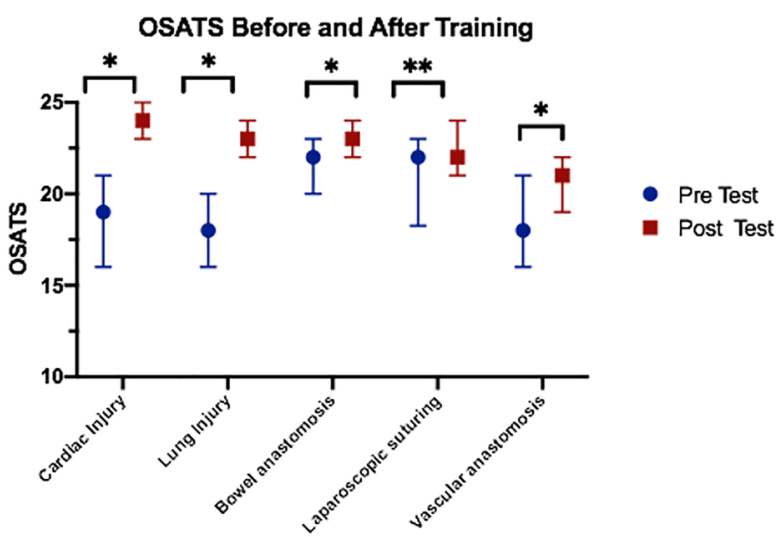

OSATS individual scores before and after training.

$*=p<0.01$

$* *=p<0.001$

Fig. 1 OSATS individual scores before and after training. $* p$-value $<0.01, * * p$-value $<0.001$

\section{Limitations}

The number of participants was limited because of geographical constraints. In some cases, trainees had to travel over a thousand miles to attend the boot camp. In addition, our country has a limited number of general surgery residents. Since the participants of this study came from 15 certified general surgery residency programs available in our country, we believe this sample is heterogeneous and representative of our reality.

On secondhand, we acknowledge a weakness in one of the scales used for assessment, the task-specific rating scales did not undergo a specific validation process.

Finally, this study contemplates assessment in simulated procedures, showing acquisition of technical skills in this scenario. Further studies are required to evaluate predictive validity with a transfer of skills from this boot camp training to the real scenario, the operating room.

\section{Conclusion}

An improvement in the objective scores, time to perform the procedure, and self-perception of surgical skills were shown, proving that this training system is effective and can be used as an effective training strategy for the acquisition of surgical skills in trauma surgery. Extremely low objective scores and level of confidence at the cardiopulmonary and lung stations, show a deficit in the training program and should be addressed. If simulation-based programs like this one are included in the first years of residency, general surgeons could have better skills and 
Table 7 Comparison of scores and time to complete the procedure before and after training

\begin{tabular}{|c|c|c|c|c|c|c|c|c|c|}
\hline Station & Pre OSATS & Post OSATS & $p$-value & Pre SRS & Post SRS & $p$-value & Pre time (s) & $\begin{array}{l}\text { Post time } \\
\text { (s) }\end{array}$ & $p$-value \\
\hline $\begin{array}{l}\text { Penetrating cardiac } \\
\text { injury }\end{array}$ & 10-24 (19) & $\begin{array}{l}17-25 \\
(24)\end{array}$ & $<0.0001$ & $2-7(5)$ & $\begin{array}{l}4-8 \\
(8)\end{array}$ & $<0.0001$ & \multicolumn{3}{|c|}{ Described in detail in Table 2} \\
\hline Penetrating lung injury & $14-25(18)$ & $\begin{array}{l}16-25 \\
(23)\end{array}$ & $<0.0001$ & $0-8(3)$ & $\begin{array}{l}2-8 \\
(8)\end{array}$ & $<0.0001$ & $\begin{array}{l}144-1083 \\
(565)\end{array}$ & $\begin{array}{l}571-1153 \\
(932)\end{array}$ & $<0.0001$ \\
\hline Bowel anastomosis & $16-25(22)$ & $\begin{array}{l}18-25 \\
(23)\end{array}$ & $<0.0001$ & $3-15(13)$ & $\begin{array}{l}8-15 \\
(14)\end{array}$ & $<0.0001$ & $\begin{array}{l}481-1150 \\
(777)\end{array}$ & $\begin{array}{l}523-1082 \\
(880)\end{array}$ & 0.0002 \\
\hline Laparoscopic suturing & $11-25(22)$ & $\begin{array}{l}12-25 \\
(22)\end{array}$ & 0.0002 & $8-21(19)$ & $\begin{array}{l}13-21 \\
(19)\end{array}$ & 0.0006 & 240-927 (593) & $\begin{array}{l}209-921 \\
(507)\end{array}$ & 0.0004 \\
\hline Vascular anastomosis & $11-24(18)$ & $\begin{array}{l}13-25 \\
(21)\end{array}$ & $<0.0001$ & $16-28(22)$ & $\begin{array}{l}19-28 \\
(23)\end{array}$ & $<0.0001$ & 511-1042 (801) & $476-1115(856)$ & 0.0006 \\
\hline
\end{tabular}

Confidence level results per station

A

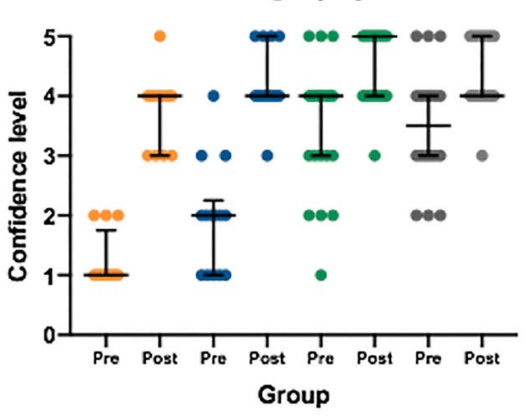

C

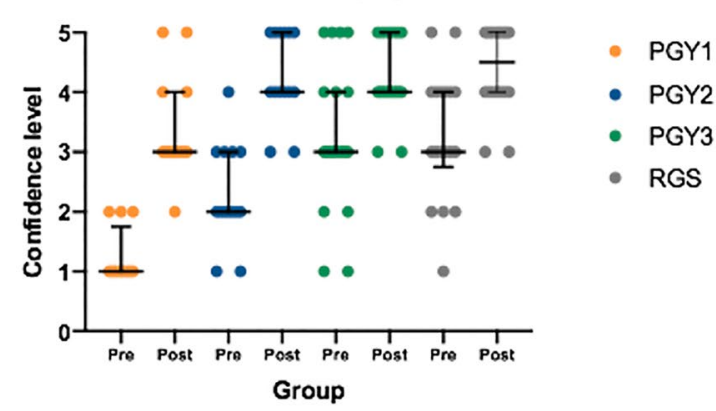

D

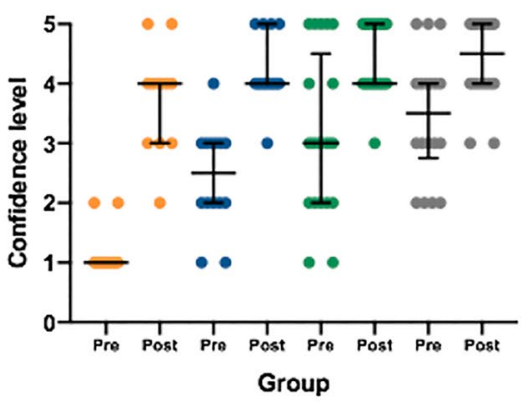

B
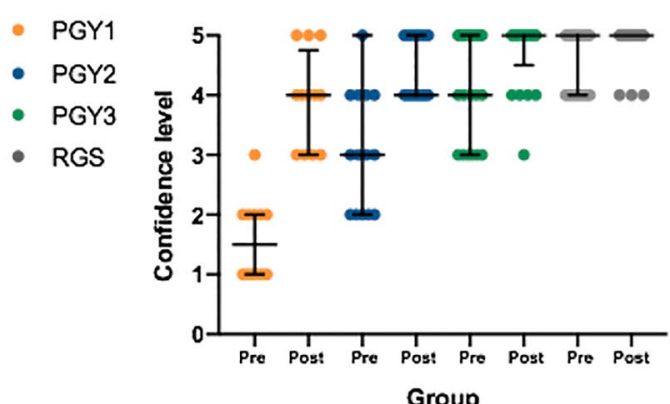

- PGY1

- $\mathrm{PGY} 2$

- PGY3

- RGS
E Laparoscopic suturing

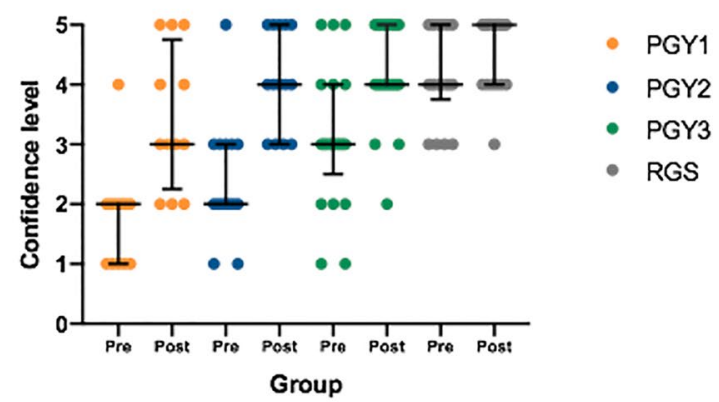

Fig. 3 A-E Confidence level results per station. $P G Y 1$ postgraduate year $1, P G Y 2$ postgraduate year 2, $P G Y 3$ postgraduate year $3, R G S$ recently graduated surgeons 


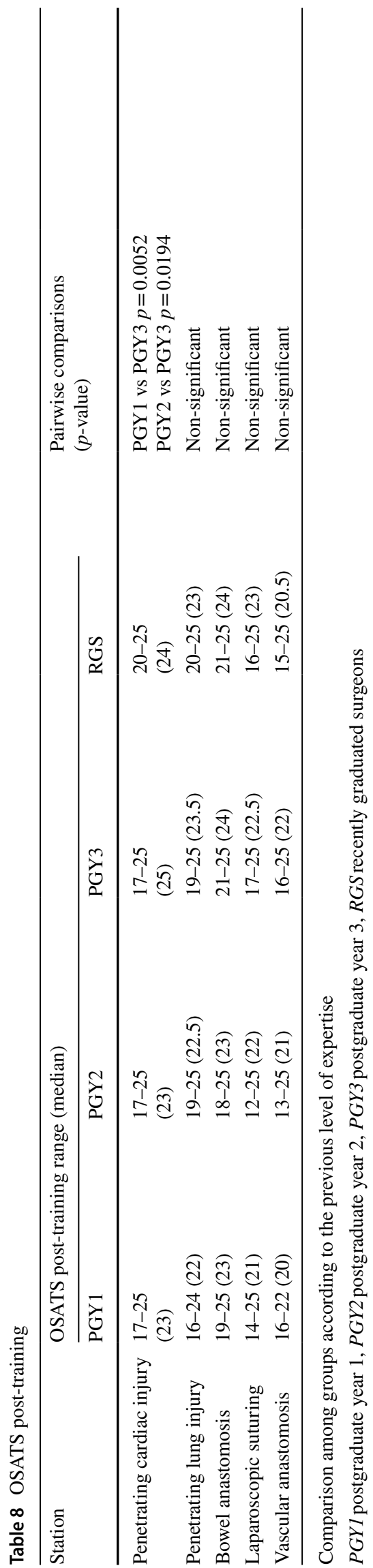

confidence when facing these extremely severe trauma scenarios.

Funding This study was funded and supported by Chilean Research Grant FONDECYT REG.1171908 from CONICYT.

\section{Declarations}

Disclosures Drs. Catalina Ortiz, Javier Vela, Caterina Contreras, Francisca Belmar, Ivan Paul, Analia Zinco, Juan Pablo Ramos, Pablo Ottolino, Pablo Achurra, Nicolas Jarufe, and Julian Varas were financed and supported by a Chilean Research Grant FONDECYT REG 1171908 from CONICYT and by the Department of Digestive Surgery, Faculty of Medicine, Pontificia Universidad Católica de Chile. Dr. Julian Varas is the Founder of Training Competence, an official spinoff startup from the Pontificia Universidad Católica de Chile. The startup and the Pontificia Universidad Católica de Chile are the owners of the rights and distribution of the C1DO1 platform used for the assessment in this study. Dr. Adnan Alseidi has no conflict of interest or financial ties to disclose.

\section{References}

1. Bedard AF, Mata LV, Dymond C, Moreira F, Dixon J, Schauer SG, Ginde AA, Bebarta V, Moore EE, Mould-Millman N-K (2020) A scoping review of worldwide studies evaluating the effects of prehospital time on trauma outcomes. Int J Emerg Med 13:64. https://doi.org/10.1186/s12245-020-00324-7

2. Callcut RA, Mell MW (2013) Modern advances in vascular trauma. Surg Clin N Am 93(941-961):ix. https://doi.org/10. 1016/j.suc.2013.04.010

3. Lerner EB, Moscati RM (2001) The golden hour: scientific fact or medical "urban legend"? Acad Emerg Med 8:758-760. https:// doi.org/10.1111/j.1553-2712.2001.tb00201.x

4. Teixeira PGR, Inaba K, Hadjizacharia P, Brown C, Salim A, Rhee P, Browder T, Noguchi TT, Demetriades D (2007) Preventable or potentially preventable mortality at a mature trauma center. J Trauma 63:1338-1346. https://doi.org/10.1097/TA.0b013e3181 $5078 \mathrm{ae}$

5. Schoeneberg C, Schilling M, Probst T, Lendemans S (2014) Preventable and potentially preventable deaths in severely injured elderly patients: a single-center retrospective data analysis of a German trauma center. World J Surg 38:3125-3132. https://doi. org/10.1007/s00268-014-2755-0

6. Mattar SG, Alseidi AA, Jones DB, Jeyarajah DR, Swanstrom LL, Aye RW, Wexner SD, Martinez JM, Ross SB, Awad MM, Franklin ME, Arregui ME, Schirmer BD, Minter RM (2013) General surgery residency inadequately prepares trainees for fellowship: results of a survey of fellowship program directors. Ann Surg 258:440-449. https://doi.org/10.1097/SLA.0b013e3182a191ca

7. Reznick RK, MacRae H (2006) Teaching surgical skills-changes in the wind. N Engl J Med 355:2664-2669. https://doi.org/10. 1056/NEJMra054785

8. Traynor O (2011) Surgical training in an era of reduced working hours. Surgeon 9(Suppl 1):S1-2. https://doi.org/10.1016/j.surge. 2011.04.003

9. Peets A, Ayas NT (2012) Restricting resident work hours: the good, the bad, and the ugly. Crit Care Med 40:960-966. https:// doi.org/10.1097/CCM.0b013e3182413bc5 
10. Aziz H, James T, Remulla D, Sher L, Genyk Y, Sullivan ME, Sheikh MR (2021) Effect of COVID-19 on surgical training across the United States: a National Survey of General Surgery residents. J Surg Educ 78:431-439. https://doi.org/10.1016/j.jsurg.2020.07. 037

11. Hope C, Reilly J-J, Griffiths G, Lund J, Humes D (2021) The impact of COVID-19 on surgical training: a systematic review. Tech Coloproctol 25:505-520. https://doi.org/10.1007/ s10151-020-02404-5

12. Munro C, Burke J, Allum W, Mortensen N (2021) Covid-19 leaves surgical training in crisis. BMJ 372:n659. https://doi.org/10.1136/ bmj.n659

13. Borgersen NJ, Naur TMH, Sørensen SMD, Bjerrum F, Konge L, Subhi Y, Thomsen ASS (2018) Gathering validity evidence for surgical simulation: a systematic review. Ann Surg 267:10631068. https://doi.org/10.1097/SLA.0000000000002652

14. Ortiz C, Belmar F, Rebolledo R, Vela J, Contreras C, Inzunza M, Ramos JP, Zinco A, Alseidi A, Varas J, Jarufe N, Achurra P (2021) Validity argument for a simulation-based objective structured clinical examination scenario for evaluation of surgical skills in trauma. J Surg Res 268:507-513. https://doi.org/10.1016/j.jss. 2021.06.069

15. Messick S (1994) Validity of psychological assessment: validation of inferences from persons' responses and performances as scientific inquiry into score meaning. ETS Res Rep Series 1994:i-28. https://doi.org/10.1002/j.2333-8504.1994.tb01618.x

16. Varas J, Mejía R, Riquelme A, Maluenda F, Buckel E, Salinas J, Martínez J, Aggarwal R, Jarufe N, Boza C (2012) Significant transfer of surgical skills obtained with an advanced laparoscopic training program to a laparoscopic jejunojejunostomy in a live porcine model: feasibility of learning advanced laparoscopy in a general surgery residency. Surg Endosc 26:3486-3494. https:// doi.org/10.1007/s00464-012-2391-4

17. Ortiz C, Vela J, Contreras C, Ávila R, Inzunza M, Quezada J, Jarry C, Ramos JP, Ottolino P, Varas J, Jarufe N, Achurra P (2020) Achievement of effective cardiopulmonary trauma surgical skills training throughout the incorporation of a low-cost and easy to implement pulsatile simulation model. Injury. https://doi.org/10. 1016/j.injury.2020.12.004
18. Spoerer S, Vela J, Contreras C, Ortiz C, Caro I, Riquelme C, Garrido F, Inzunza Ó, Ramos JP, Achurra P, Varas J, Jarufe N (2021) Elaboración de un simulador de trauma torácico a partir de un torso cadavérico utilizando tecnología de imágenes digitales e impresión 3D. Rev Cir. https://doi.org/10.35687/s2452-45492 021003906

19. Perkis JPR, Lavarte PRO, Alarcón CA, Cabrera JER, Ponce CEA, Moreira FPS, Ramirez LC, Tirado PA, Fernadez AD (2021) Primer registro de trauma en Chile. Análisis de 2 años en un hospital público. Rev Cir. https://doi.org/10.35687/s2452-45492 021001703

20. Vela J, Cárcamo L, Contreras C, Arenas C, Ramos JP, Rebolledo R, Varas J, Martínez J, Jarufe N, Achurra P (2021) Self-confidence on acquired surgical skills to deal with severe trauma patients in recently graduated surgeons. Arq Bras Cir Dig 34:e1561. https:// doi.org/10.1590/0102-672020210001e1561

21. Vera M, Kattan E, Cerda T, Niklitshek J, Montaña R, Varas J, Corvetto MA (2021) Implementation of distance-based simulation training programs for healthcare professionals: breaking barriers during COVID-19 pandemic. Simul Healthc. https://doi.org/10. 1097/SIH.0000000000000550

22. Quezada J, Achurra P, Jarry C, Asbun D, Tejos R, Inzunza M, Ulloa G, Neyem A, Martínez C, Marino C, Escalona G, Varas J (2019) Minimally invasive tele-mentoring opportunity-the mito project. Surg Endosc. https://doi.org/10.1007/ s00464-019-07024-1

23. Hatala R, Cook DA, Brydges R, Hawkins R (2015) Constructing a validity argument for the Objective Structured Assessment of Technical Skills (OSATS): a systematic review of validity evidence. Adv Health Sci Educ Theory Pract 20:1149-1175. https:// doi.org/10.1007/s10459-015-9593-1

24. Likert R (1932) A technique for the measurement of attitudes. Arch Psychol 22(140):55-55

25. American College of Surgeons ATOM. https://acschile.cl/atomadvanced-trauma-operative/. Accessed 26 Dec 2021

Publisher's Note Springer Nature remains neutral with regard to jurisdictional claims in published maps and institutional affiliations. 